\title{
Increased airway responsiveness in children of low birth weight at school age: effect of topical corticosteroids
}

\author{
K N Chan, M Silverman
}

\begin{abstract}
The effect of treatment with topical inhaled corticosteroids was assessed in $\mathbf{1 5}$ children of low birth weight (mean (SD) birth weight 1435 (268) g, gestational age $30.5(2.9)$ weeks, age at study $8.2(0.4)$ years) who were symptomatic and showed a positive airway response to histamine aerosol. The study was of a double blind, placebo controlled, crossover design with four week long treatment periods with inhaled beclomethasone dipropionate $(400 \mu \mathrm{g}$ daily) or placebo. Daily symptom scores were recorded and physiological measurements were performed at the beginning and end of each treatment period. There was no significant difference in respiratory symptom score, baseline airway function, or the airway response to histamine between treatment periods. The findings argue against an inflammatory basis for airway hyper-responsiveness in these children and raise questions as to its pathophysiological basis.

(Arch Dis Child 1993; 69: 120-124)
\end{abstract}

Airway hyperresponsiveness is a characteristic feature of asthma. ${ }^{1}$ It has also been found in long term survivors of low birth weight. ${ }^{23}$ Using the cumulative inhaled histamine dose which caused a $20 \%$ decrease in airway function from the baseline $\left(\mathrm{PD}_{20}\right)$ as an index of airway responsiveness, we found that $44 \%$ of 7 year old low birthweight children had a $\mathrm{PD}_{20}$ of less than $3 \mu \mathrm{mol}$ compared with only $22 \%$ of a reference group of the same age. ${ }^{3}$ There was a close association between airway responsiveness and respiratory symptoms in these children. Sixty per cent of those with a positive airway response as defined here were reported independently by their parents to have troublesome cough or wheeze.

In asthma, inflammation plays an important part in airway hyper-responsiveness. A close relation between the degree of airway inflammation and the degree of airway responsiveness has been confirmed. ${ }^{4}$ The anti-inflammatory effects of inhaled steroids have been shown to be effective in reducing the level of airway responsiveness and symptoms. ${ }^{56}$ The pathophysiological basis for airway hyper-responsiveness in low birthweight children remains debatable. ${ }^{23}$ It is possible that inflammatory processes might contribute; alternatively, mechanical factors resulting from an abnormal pattern of lung growth in infancy may be responsible.

The objective of this study was to investigate the effect of beclomethasone dipropionate, a potent, topical, anti-inflammatory drug, on airway responsiveness, airway function, and symptoms in symptomatic low birthweight children with measurable bronchial responsiveness, as an indirect means of determining the likelihood that airway inflammation might underlie their airway dysfunction.

\section{Methods}

SUBJECTS

Children recruited for this clinical trial were those who had taken part in an earlier cohort study at the age of 7 years, who were symptomatic (wheeze or troublesome cough, with or without colds), and who had shown a positive airway response to histamine $\left(\mathrm{PD}_{20} \leqslant 3 \mu \mathrm{mol}\right){ }^{37}$ Based on these criteria, a total of 30 children in the low birthweight cohort were eligible for inclusion.

Children who were receiving or had received regular prophylactic treatment for asthma, or who had received a course of steroids by mouth within the previous three months for any medical disorder were excluded, but not those who were receiving bronchodilators by inhalation or by mouth only. Those who had common colds began the study at a later date.

\section{DRUGS}

The study was of a double blind, placebo controlled, crossover design. The drug chosen for this trial was inhaled beclomethasone dipropionate (Glaxo UK) at a dose of $200 \mu \mathrm{g}$ twice daily for four weeks. Active and placebo drugs were identical in appearance and taste and were administered by Becotide Diskhaler (Glaxo UK).

Each child taking part in the study was carefully taught the inhalation technique. Only those who were capable of using the Diskhaler correctly were included in the study.

\section{PROTOCOL}

Subjects were randomly allocated to one of two treatment groups: group A received beclomethasone dipropionate $200 \mu \mathrm{g}$ twice daily for four weeks followed by placebo for four weeks; group $B$ received placebo for four weeks followed by active treatment with beclomethasone dipropionate $200 \mu \mathrm{g}$ twice daily for four weeks. Clinic visits for physiological measurements took place at the start of the study, and at the end of the first 
and the second four week treatment periods. Spent rotadisks were collected to check for compliance with treatment. Physiological measurements were delayed for six to 24 hours for those who had taken bronchodilators.

Airway responsiveness to histamine expressed as $\mathrm{PD}_{20}$ was determined at each clinic visit by the technique of Yan $e t a l^{8}$ using the dose schedule and protocol reported previously.' In this protocol, although a $\mathrm{PD}_{20}$ of $\leqslant 3 \mu \mathrm{mol}$ was taken as indicative of a positive airway response, a maximum cumulative histamine dose of $6 \mu \mathrm{mol}$ was used. By using a curve fitting routine, values of $\mathrm{PD}_{20}$ up to double the maximum dose of histamine administered could be calculated by extrapolation. The output characteristics of the hand held DeVilbiss No 40 nebulisers used have been reported elsewhere. ${ }^{10}$

Forced expiratory volume in one second $\left(\mathrm{FEV}_{1}\right)$ and forced vital capacity (FVC) were measured at each clinic visit by spirometry (Vitalograph). The best of three recordings was used for data analysis.

Self recording of the peak expiratory flow rate (PEFR) was carried out each day first thing in the morning and in the evening using a mini-Wright peak flow meter (Airmed, Harlow). The best of three blows was recorded on each occasion.

Respiratory symptoms, specifically cough at night $(0-2)$ and during the day $(0-2)$, wheeze at night $(0-3)$ and during the day $(0-3)$, and wheeze or cough after exercise (0-2) were recorded on a diary card, giving a maximum daily score of 12 . Other medical treatment during the trial period was documented.

The study was approved by the ethics committee of the Hammersmith and Queen Charlotte's Special Health Authority and a parent of each subject gave informed written consent. Before beginning the study, the child's family doctor was also approached to determine that he had no objections to the study.

\section{Data analysis}

STUDY SIZE

As the main interest in this study was to examine the effects of inhaled steroids on airway responsiveness, the calculation of study size was based primarily on the changes in the $\mathrm{PD}_{20}$. This took into account a standard deviation of $0.62 \mu \mathrm{mol}$ for the $\log _{e}$ of $\mathrm{PD}_{20}$ based on the 195 histamine provocation tests in children who had shown a measurable response to a maximum cumulative dose of $6 \mu \mathrm{mol}$ in the previous studies ${ }^{37}$ and the repeatability of the technique of Yan et al in determining airway responsiveness, which had been determined between days to be within one doubling dose.$^{89}$ Assuming that such a change in $\mathrm{PD}_{20}$ after a four week course of active treatment was considered to be clinically important, and accepting a type $I$ error ( $p$ value) of 0.05 and a type II error of $0 \cdot 20$ (power of study of $0 \cdot 80$ ), the required study size was 12 using one tailed $t$ statistics. The latter was chosen because if there was any effect with treatment it would be in the direction of reducing responsiveness. Natural logarithmic transformations were made for all calculations including $\mathrm{PD}_{20}$.

\section{EVALUATION OF TREATMENT EFFECTS}

In examining the effects of a two period, crossover clinical trial, the treatment period was compared with the placebo period, in accordance with the method described by Hills and Armitage." Two assumptions were implicit in the comparisons. Firstly, the change due to treatment was the same for all subjects. Secondly, this change was unaffected by the order in which the active treatment or placebo was given. Data were examined to exclude possible time trend (period) as well as carryover effects. The treatment effects for the two periods were then estimated jointly. Student's $t$ test was used to examine the effects of treatment on various outcome variables. A p value of $<0.05$ was taken as indicative of statistical significance.

In addition to the effects of inhaled beclomethasone dipropionate on airway responsiveness, we were also interested in its effects on respiratory symptoms and airway function. These were analysed separately. The self recorded PEFR and the $F_{1} V_{1}$ recorded in hospital clinics were taken as the outcome parameters for airway function. For self recorded PEFR, a daily mean was calculated, excluding the first seven days from each of the four week periods to allow for training and washout effects. Similarly, a mean daily symptom score was calculated from the diary card excluding the first week of each period.

\section{Results}

SUBJECTS

Of the 30 children who met the recruitment criteria (that is, they were symptomatic and had a $\mathrm{PD}_{20} \leqslant 3 \mu \mathrm{mol}$ at an age of 7 years), the parents of 18 subjects agreed to take part. One child withdrew and two children did not have airway response data. Fifteen subjects completed the study. The study was carried out over a period of four months at a mean (SD) age of $8 \cdot 2$ $(0 \cdot 4)$ years. Eight children received active treatment in the first four week period (group A) and seven in the second four week period (group B). The mean (SD) birth weight and gestational age of the study subjects were 1435 (268) $\mathrm{g}$ and $30 \cdot 5$ (2.9) weeks respectively. Three children had received treatment for asthma in the past, but none required regular treatment. There was no difference in clinical and perinatal data between groups $A$ and $B$ (tables 1 and 2 ). No study subject recorded side effects in the course of the study.

\section{AIRWAY RESPONSIVENESS}

All the children showed a $\mathrm{PD}_{20}$ of $\leqslant 6 \mu \mathrm{mol}$ at recruitment, though the overall level of airway responsiveness was significantly less than that recorded in the previous study. The mean (SD) $\log _{\mathrm{e}} \mathrm{PD}_{20}$ at 7 and 8.2 years was $-0.45(1 \cdot 25)$ and $0.75(1.11) \mu \mathrm{mol}$ respectively $(\mathrm{p}<0.01)$. Three children had a $\mathrm{PD}_{20}$ greater than $6 \mu \mathrm{mol}$; their results were therefore estimated by extrapolation to the next doubling dose. ${ }^{12}$ There was no significant difference in $\mathrm{PD}_{20}$ between treatment periods with beclomethasone dipropionate and placebo (table 3 ). In fact, the $\mathrm{PD}_{20}$ was minimally lower (more responsive) with active treat- 
Table 1 Clinical data of subjects who completed the beclomethasone trial

\begin{tabular}{ccccccccccc}
\hline Group & No & $\begin{array}{l}\text { Age } \\
\text { (years) }\end{array}$ & $\begin{array}{l}\text { Height } \\
(\mathrm{cm})\end{array}$ & Sex & $\begin{array}{l}\text { Personal } \\
\text { asthma }\end{array}$ & $\begin{array}{l}\text { Parental } \\
\text { asthma }\end{array}$ & $\begin{array}{l}\text { Skin } \\
\text { test }\end{array}$ & $\begin{array}{l}F E V_{1} \\
(l)\end{array}$ & $\begin{array}{l}F V C \\
(l)\end{array}$ & $\begin{array}{l}P D_{20} \\
(\mu m o l)\end{array}$ \\
\hline A (active/ & 1 & 8.7 & 125.5 & $\mathrm{M}$ & - & - & - & 1.70 & 2.00 & 6.0 \\
placebo) & 2 & 8.5 & 130.0 & $\mathrm{M}$ & - & + & - & 1.05 & 1.45 & 4.3 \\
& 3 & 8.3 & 122.5 & $\mathrm{M}$ & - & + & + & 0.80 & 0.90 & 0.1 \\
& 4 & 8.2 & 125.0 & $\mathrm{~F}$ & + & + & + & 1.30 & 1.55 & 1.2 \\
& 5 & 8.2 & 118.0 & $\mathrm{~F}$ & - & - & - & 1.05 & 1.15 & 1.3 \\
& 6 & 7.8 & 124.0 & $\mathrm{M}$ & - & - & - & 1.30 & 1.50 & 3.7 \\
& 7 & 7.7 & 122.0 & $\mathrm{M}$ & - & - & - & 1.00 & 1.20 & 0.7 \\
B (active/ & 8 & 7.7 & 123.0 & $\mathrm{M}$ & - & - & - & 1.50 & 1.65 & 2.5 \\
placebo) & 9 & 8.7 & 125.0 & $\mathrm{M}$ & - & + & + & 1.60 & 1.80 & 3.2 \\
& 10 & 8.7 & 135.0 & $\mathrm{M}$ & - & - & + & 1.55 & 1.80 & 4.5 \\
& 11 & 8.5 & 129.0 & $\mathrm{~F}$ & - & - & - & 1.35 & 1.45 & 3.8 \\
& 12 & 8.4 & 136.0 & $\mathrm{~F}$ & - & - & - & 1.30 & 1.75 & 5.4 \\
& 13 & 8.0 & 126.0 & $\mathrm{M}$ & + & + & + & 1.10 & 1.70 & 3.4 \\
& 14 & 7.9 & 122.5 & $\mathrm{M}$ & - & - & + & 1.40 & 1.75 & 0.5 \\
& 15 & 7.9 & 121.0 & $\mathrm{~F}$ & - & - & - & 0.70 & 1.15 & 4.8 \\
\hline
\end{tabular}

*A positive skin test is defined as the presence of a weal of at least $2 \mathrm{~mm}$ in diameter in response to prick test to one of three allergens (namely housedust mite (Dermatophagoides pteronyssinus), group B pollens, and cat fur) in the absence of a response to the control solution (Bencard).

Table 2 Perinatal data of subjects who completed the beclomethasone trial

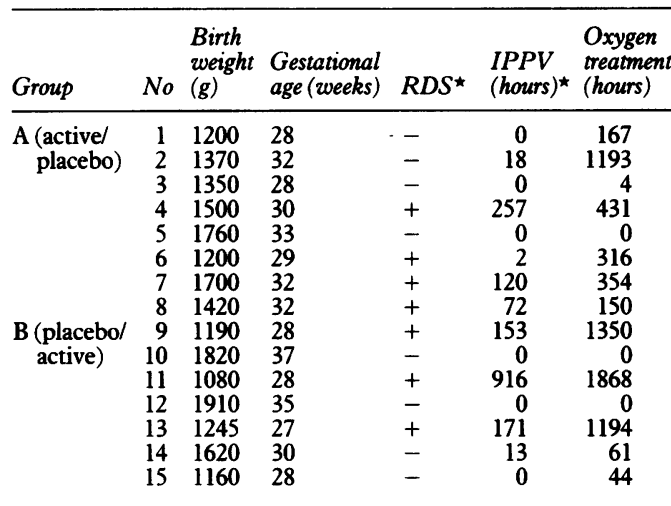

$\star$ RDS $=$ Respiratory distress syndrome; IPPV =intermittent positive pressure ventilation; no patient developed an air leak.

ment than with placebo (figure). There were no significant period or carryover effects (table 3 ).

\section{SYMPTOM SCORE}

The self recorded symptom score was variable between subjects, ranging from 0 (no symptoms) to 145 (frequent symptoms) over a three week period. During the active treatment period nine children recorded a reduction in symptom score but six recorded an increase in score. There were no significant period or carryover effects and no difference in the mean daily symptom score between active and placebo treatments (table 3 ).

\section{LUNG FUNCTION}

The mean daily PEFR was almost identical for the two treatment periods. Eight children recorded a slightly higher PEFR but seven showed the opposite trend during the active treatment compared with the placebo period.
There was a small but statistically insignificant increase in $\mathrm{FEV}_{1}$ after treatment with beclomethasone dipropionate compared with that with placebo. No significant period or carryover effects were shown (table 3 ).

\section{Discussion}

\section{STUDY DESIGN AND SUBJECTS}

We found no significant effect of inhaled beclomethasone dipropionate on the airway responsiveness to histamine or on respiratory symptoms and airway function in low birthweight children of school age who were symptomatic and had shown a positive airway response to histamine in an earlier study. There were no period or carryover effects. If the assumption is true that topical corticosteroids reduce pulmonary epithelial inflammation and associated oedema, then these results suggest that inflammatory processes were not responsible for airway dysfunction in this group of children.

Although the original number of subjects who met the study criteria was ample for the purpose of this study, just over half agreed to take part. The final number was nevertheless sufficient to detect a true doubling in $\mathrm{PD}_{20}$ if this had occurred, at a power of $\mathbf{0 . 9 0}$. The upper airway confidence limit for the treatment effect on $\mathrm{PD}_{20}$ corresponds to a multiplicative factor of $\mathbf{1 \cdot 9 2}$. We can thus be fairly confident that treatment with inhaled beclomethasone dipropionate at a dose of $200 \mu \mathrm{g}$ twice daily for four weeks results in little or no improvement in airway responsiveness in these children.

A double blind, placebo controlled, crossover design was chosen for the study because it was simple to carry out and, with treatment effects being estimated from within subject observations, the results were not affected by the large between subject measurement error. Consequently, the number of subjects required for the study was kept to a minimum.

\section{IMPLICATIONS}

Non-specific airway hyper-responsiveness is a feature of many airway disorders, of which asthma and chronic airflow obstruction are two of the better known examples. A large number of otherwise healthy low birthweight schoolchildren have increased airway responsiveness compared with a random population of schoolchildren of the same age. ${ }^{3}$ The pathophysiological basis of the airway responsiveness observed in these children remains debatable. ${ }^{23}$ It is not known whether it is due to persistent airway inflammation and, if so, whether the effect could potentially be reversible with topical anti-inflammatory treatment. An alternative is

Table 3 Effect of inhaled beclomethasone on outcome variables

\begin{tabular}{|c|c|c|c|c|c|}
\hline Parameter & $\begin{array}{l}\text { Mean }(S D) \\
\text { beclomethasone }\end{array}$ & $\begin{array}{l}\text { Mean }(S D) \\
\text { placebo }\end{array}$ & $\begin{array}{l}\text { Mean }(95 \% C I) \\
\text { treatment effect }\end{array}$ & $\begin{array}{l}\text { Mean }(95 \% C I) \\
\text { period effect }\end{array}$ & $\begin{array}{l}\text { Mean }(95 \% \text { CI) } \\
\text { carryover effect }\end{array}$ \\
\hline $\begin{array}{l}\text { Symptom score } \\
\text { PEFR }(1 / \mathrm{min}) \\
\mathrm{FEV}_{1}(\mathrm{l}) \\
\log _{\mathrm{e}} \mathrm{PD}_{20}(\mu \mathrm{mol})\end{array}$ & $\begin{array}{l}1.22(1 \cdot 36) \\
202(37) \\
1.30(0 \cdot 29) \\
0.76(1.21)\end{array}$ & $\begin{array}{l}1.64(1.67) \\
200(41) \\
1 \cdot 25(0 \cdot 28) \\
0.84(0.81)\end{array}$ & $\begin{array}{c}-0.51(-1.49 \text { to } 0.48) \\
2(-17 \text { to } 21) \\
-0.04(-0.14 \text { to } 0.05) \\
0.08(-0.49 \text { to } 0.65)\end{array}$ & $\begin{array}{c}1.30(-0.32 \text { to } 2.29) \\
-11(-30 \text { to } 8) \\
0(-0.1 \text { to } 0.09) \\
0(-0.57 \text { to } 0.57)\end{array}$ & $\begin{array}{l}0.94(-1.27 \text { to } 3.15) \\
-24(-102 \text { to } 55) \\
0.08(-0.71 \text { to } 0.54) \\
0.58(-1.41 \text { to } 2.57)\end{array}$ \\
\hline
\end{tabular}

${ }^{\star}$ Symptom score $=$ daily mean score. $\mathbf{C I}=$ confidence intervals. 


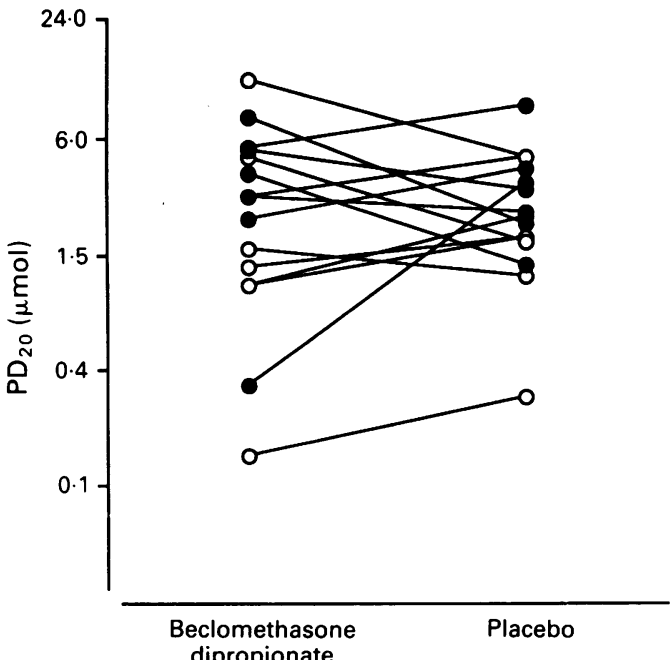

$P D_{20}$ ( $\log _{\mathrm{e}}$ scale) after four week long treatment periods with beclomethasone propionate and placebo. Subjects who had beclomethasone-placebo and placebo-beclomethasone treatment are indicated by open and closed circles respectively.

that it is the result of structural airway narrowing related to preterm birth, perinatal insults, or disturbed lung growth in infancy.

In asthma, airway responsiveness is strongly related to the symptoms and the level of treatment required. ${ }^{12} 13$ There is a growing body of evidence suggesting that inflammation plays a crucial part in the manifestations of asthma ${ }^{4}$ and there is a close association between the degree of airway inflammatory changes and the degree of airway responsiveness. ${ }^{413}$ Treatment with topical corticosteroids has been shown to reduce the level of airway responsiveness and respiratory symptoms. ${ }^{614}$

We studied the response of low birthweight children to treatment with beclomethasone dipropionate for two reasons: firstly to determine the symptomatic benefits of treatment and secondly to provide data which may allow the mechanism of airway dysfunction in these children to be determined. The children recruited for this study were those who were considered most likely to benefit, namely those who were symptomatic and had previously shown a positive airway response to histamine.

We would have expected to see a reduction in bronchial responsiveness after four weeks of treatment in a comparable group of children with asthma of this age. We did not recruit matched controls, however, and it is impossible, given methodological differences in bronchial challenge techniques, to make direct comparisons with other published work. Ideally, a group of children with mild, untreated asthma with a similar degree of bronchial responsiveness should have been recruited.

The lack of effect of inhaled beclomethasone dipropionate argues against an inflammatory basis for airway responsiveness in low birthweight children. Because of logistical difficulties, a short term bronchodilator response was not incorporated into the study. We are therefore unable to say if their increased airway responsiveness was due to short term bronchial smooth muscle irritability of non-inflammatory origin. Unlike the situation in childhood asthma, however, airway responsiveness in these low birth- weight children correlated strongly with the level of airway function, though there was no overall gross abnormality in lung function.

Our results are remarkably similar to those seen in chronic airflow obstruction in adults. ${ }^{15}$ In the latter, the response to treatment with inhaled steroids and bronchodilators is variable and cannot be predicted from the level of airway responsiveness. ${ }^{16} 17$ In chronic airflow obstruction, the prognosis in the absence of reversibility may be poorer than for asthma.

The results contrast markedly with the beneficial effects of corticosteroids on chronic lung disease in early infancy. In the early inflammatory phase in ventilator dependent neonates ${ }^{18}$ and in the subacute phase of resolution - that is, wheezy preterm infants ${ }^{19}$ - the efficiency of corticosteroids has been demonstrated. This suggests possible differences in the pathophysiology of airway dysfunction at different stages in the natural history of chronic lung disease.

In conclusion, there was no significant effect of treatment with a topical corticosteroid in symptomatic low birthweight schoolchildren with increased airway responsiveness. The long term implications of airway hyper-responsiveness in these children remain to be determined. We hypothesise that the increased airway responsiveness observed in long term survivors of low birth weight is not an effect of chronic inflammation and airway oedema, but is due to abnormal pulmonary development after preterm birth and possibly to neonatal intensive care. ${ }^{20}$ The continued follow up of these children is important to resolve the question.

We thank the low birthweight children and their parents for their enthusiastic cooperation. We are grateful to the National Asthma Campaign, The Good Neighbours Trust, Sue Hammerson Trust, and Glaxo UK Ltd for financial support.

1 Silverman $M$, Wilson NM. Bronchial responsiveness in children. A clinical view. In: Milner AD, Martin J, eds. Pediatric and neonatal respiratory medicine. London: Butterworth, 1985: 161-89.

2 Bertrand JM, Riley SP, Popkin J, et al. The long-term pulmonary sequelae of prematurity: the role of familial airway hyperreactivity and the respiratory distress syndrome. N Engl f Med 1985; 312: 742-5.

3 Chan KN, Elliman A, Bryan EM, Silverman M. Clinical significance of increased airway responsiveness in children of significance of increased airway responsiveness in chil
low birthweight. Pediatr Pulmonol 1989; 7: 251-8.

4 Chung KF. Role of inflammation in the hyperreactivity of the airways in asthma. Thorax 1986; 41: 657-62.

5 Barnes PJ. Effect of corticosteroids on airway hyperresponsiveness. Am Rev Respir Dis 1990; 141: s70-6.

6 Kerrebijn KF, van Essen-Zandvliet EEM, Neijens HJ. Effect of long term treatment with inhaled corticosteroids and beta agonists on the bronchial responsiveness in children with asthma. F Allergy Clin Immunol 1987; 79: 37-41.

7 Chan KN, Elliman A, Bryan EM, Silverman M. Respiratory symptoms in children of low birthweight. Arch Dis Child 1989; 64: 1294-304.

8 Yan K, Salome C, Woolcock AJ. Rapid method for measurement of bronchial responsiveness. Thorax 1983; 38: 760-5.

9 Chan KN, Noble-Jamieson CM, Elliman A, Bryan EM, Aber VR, Silverman M. Airway responsiveness in low birthweight children and their mothers. Arch Dis Child 1988; 63 905-10

10 Chan KN, Clay MM, Silverman M. Output characteristics of DeVilbiss No 40 hand-held jet nebulisers. Eur Respir $\mathcal{F} 1990$ 3: 1197-201.

11 Hills $M$, Armitage $P$. The two-period cross-over clinical trial. Br f Clin Pharmacol 1979; 8: 7-20.

12 Cockcroft DW, Killion DN, Mellon JJA, et al. Bronchia reactivity to inhaled histamine: a method and a clinical survey. Clinical Allergy 1977; 7: 235-43.

13 Hargreave FE, Ramsdale EH, Kirby JG, et al. Asthma and the role of inflammation. Eur $\mathcal{F}$ Respir Dis 1986; 69 (suppl): 16-21.

14 Boner AL, Piacentini GL, Bonizzato C, et al. Effect of inhaled beclomethasone dipropionate on the bronchial hyperreactivity in asthmatic children during maximal allergen exposure. Pediatr Pulmonol 1991; 10: 2-5. 
15 Ramsdale EH, Morris MM, Roberts RS, et al. Bronchia responsiveness to methacholine in chronic bronchitis: relationship to airflow obstruction and cold air responsiveness. Thorax 1984; 39: 912-8.

16 Oppenheimer EA, Rigatto M, Fletcher GM. Airways obstruction before and after isoprenaline, histamine and prednisone in patients with chronic obstructive bronchitis. Lancet 1968; i: $552-7$.

17 James AL, Finucane KE, Ryan G. Bronchial responsiveness, lung mechanics, gas transfer, and corticosteroid response in patients with chronic airflow obstruction. Thorax 1988; 43: 916-22.

18 Jones $R$ (Collaborative dexamethasone trial group). Dexamethasone therapy in neonatal chronic lung disease: an internal placebo-controlled trial. Pediatrics 1991; 88: 421-7. 19 Yuksel B, Greenough A. Randomised trial of inhaled steriods in preterm infants with respiratory symptoms at follow up. Thorax 1992; 47: 910-3.

20 Chan KN, Noble-Jamieson CM, Elliman A, Bryan EM, Silverman $M$. Lung function in children of low birthweight. Arch Dis Child 1989; 64: 1284-93.

\section{Interferon alpha-2a and 'alarming haemangiomas'}

Haemangiomas (see Archivist 1992 p 723) are said to occur in some $10 \%$ of term babies and over $20 \%$ of extremely premature babies. Complete resolution occurs in over $50 \%$ by the age of 5 years and over $70 \%$ by seven years. 'Alarming haemangiomas' is a term that has been used to describe those which involve internal organs such as the liver, those which impose on vital structures such as the eye or the airway, those which are big enough to cause high output heart failure, and those which cause platelet sequestration (Kassabach-Merritt syndrome). Such lesions are often treated with high dose steroids but response is not assured. In one study response was excellent in $30 \%$, doubtful in $40 \%$, and nil in the other $30 \%$. For the most 'alarming' lesions mortality rates of more than $30 \%$ are quoted so clearly there is a need for more effective treatment.

During trials of interferon alpha-2a in patients with AIDS it was noticed that Kaposi's sarcoma, a vascular tumour, often regressed. This led to several reports of childhood haemangiomas apparently responding to this treatment and a recent paper from Boston published in the New England Fournal of Medicine (R Alan B Ezekowitz and colleagues, 1992; 326: 1456-63) describes the effects of treating 20 children, all of whom had haemangiomas that were a threat to life or vision and had been treated unsuccessfully with corticosteroids. The children ranged in age from 3 weeks to 2 years at the start of treatment. Ten had destructive lesions of the neck or face or airway obstruction. Three had lesions affecting the eye, four had Kassabach-Merritt syndrome, and three had visceral lesions involving the liver, the heart, or the brain.

Interferon alpha-2a was given by subcutaneous injection at a dose of up to 3 million units $/ \mathrm{m}^{2}$ of body surface area daily for between one and 13 months. One child with Kassabach-Merritt syndrome failed to respond and died at the age of 3 months and one with lesions affecting the eyelids had only $20 \%$ regression in one lesion. The other 18 children all showed over $50 \%$ reduction in the size of the lesions after treatment for between two and 13 months. In four the lesions regressed completely for between two and 13 months. In the three patients with Kassabach-Merritt syndrome whose coagulopathy responsed it did so at five, seven, and 10 days after starting treatment with interferon alpha-2a. One child was treated for 32 weeks and had a normal platelet count and a 50\% reduction in the size of the lesion but two weeks after the treatment was stopped the platelet count was $6.0 \times 10^{9} / 1$ and the haemangioma began to grow again. Within three days of restarting treatment the platelet count was normal and the lesion began to regress again. All the patients had some fever in the first week of treatment and one developed transient neutropenia. One had some necrosis of the skin over the lesion. No long term toxicity was noted on follow up for between five and 30 months (mean 16 months) after stopping treatment.

Although this was an uncontrolled trial the authors present convincing evidence that the treatment worked. It seems very unlikely from the known natural history of these lesions that such results could have occurred spontaneously. These 'alarming' lesions are not common but this work appears to offer an exciting new treatment prospect.

ARCHIVIST

PS. For a review of the scientific basis of 'angiogenesis' see $L$ Schweigerer and T Fotsis. Angiogenesis and angiogenesis inhibitors in paediatric diseases. Eur F Pediatr 1992; 151: Angiog. 